\title{
Tinnitus: mechanisms, measures and sound treatments
}

\author{
Pedro Cobo Parra \\ Instituto de Tecnologías Físicas y de la Información (ITEFI, CSIC) \\ pedro.cobo@csic.es
}

\begin{abstract}
Sumitted: 16/04/2015. Accepted: 16/07/2015. Available on line: 13/06/2016
Citation / Cómo citar este artículo: Pedro Cobo Parra. Tinnitus: mechanisms, measures and sound treatments. Loquens, 2(2), e024. doi: http://dx.doi.org/10.3989/loquens.2015.024
\end{abstract}

\begin{abstract}
Tinnitus is the auditory perception of sounds in the absence of any external source. Tinnitus that occurs every day for more than five minutes is reported by $10-15 \%$ of the population, and for 1 to $2 \%$ it is a handicap that interferes significantly with their quality of life (severe tinnitus). Despite the intensive research into therapeutic options, including surgery, pharmacotherapy, and electrical and acoustical stimulation, there is no approved treatment for tinnitus at present. Although the exact origin of tinnitus is still unknown, it seems to be the correlate of maladaptive attempts of the brain at reorganization due to distorted sensory input (brain plasticity). This theory is consistent with the fact that most tinnitus is associated with hearing loss. Acoustical therapies try to take advantage of this plasticity, stimulating properly the auditory system to produce tinnitus relief.

Several sound therapies are reviewed in this paper, concluding that the so-called Enriched Acoustic Environment (namely a sequence of gammatones, each one with random frequency and amplitude matched to the hearing loss at this frequency) provides the most refined and selective stimulus for the tinnitus patient. Therefore, the hearing loss curve of the patient is needed to design this sound stimulus.
\end{abstract}

Keywords: Hearing Loss; tinnitus; sound therapies.

RESUMEN: Acúfenos: mecanismos, medidas y tratamientos sonoros. El acúfeno consiste en la percepción de un sonido fantasma (un zumbido continuo dentro de la cabeza), sin una fuente externa que lo produzca. Para apreciar la importancia del tema hay que tener en cuenta que aproximadamente un 1-2 \% de la población padece de acúfeno severo, y que a día de hoy no existe ninguna medicina que lo cure. Todavía no se conoce el origen exacto del acúfeno, aunque se supone que se produce por un mecanismo de compensación homeostático del sistema auditivo central ante una pérdida auditiva periférica (plasticidad cerebral). Las terapias acústicas pretenden revertir esta plasticidad cerebral estimulando el sistema auditivo con un sonido apropiado para reducir la molestia del acúfeno.

En este artículo se revisan varias terapias acústicas y se concluye que la más apropiada consiste en una secuencia de tonos gamma de frecuencia aleatoria dentro de la banda de audio, con amplitud proporcional a su pérdida auditiva a esa frecuencia (un Ambiente Acústico Enriquecido). Por tanto, para su diseño se requiere la curva de pérdidas (HL) del paciente en cada uno de los oídos.

Palabras clave: Pérdidas Auditivas; acúfenos; terapias sonoras.

\section{INTRODUCTION}

The prevalence of hearing problems in the Western world has, due to aging of the population, doubled over the past 30 years (Knipper, Van Dijk, Nunes, Rüttiger, \& Zimmermann, 2013). Thereby, hearing loss (either noise induced: NIHL, or age related: ARHL) is an important factor that worsens over time. Hearing Loss (HL) is usually measured as an increase, expressed in decibels (dB), of the hearing thresholds.
Tinnitus is the medical term for the auditory perception of sounds in the absence of surrounding sounds. It can be divided into objective and subjective. Objective tinnitus is one which can be perceived emanating from the ears by a clinician (with an stethoscope, for instance), and can arise from underlying pathologies, such as altered blood flow or increased blood turbulence near the ears, intracranial hypertension, atherosclerotic carotid arteries, and others. On the other hand, it is believed that subjective tinnitus is a result of neuronal hyperactivity in

Copyright: (C) 2015 CSIC This is an open-access article distributed under the terms of the Creative Commons Attribution-Non Commercial (by-nc) Spain 3.0 License. 
the central auditory system as a result of damage to peripheral auditory input structures (Eggermont, 2012). Objective tinnitus can be effectively treated by surgical intervention and will not be considered here anymore. Therefore, tinnitus is usually utilised as equivalent to subjective tinnitus.

This auditory disorder is characterized by perception of internally generated "phantom auditory sensations" without the trigger of an external stimulus (Soleymani et al., 2011). It is an uncomfortable symptom affecting severely the quality of life of people, and presents great variety: a rustling, whistling, ringing, murmuring, or humming sound which can come in high or low tones, be loud or soft, and be continuous or interrupted (Holm, Staal, Mooij, \& Albers, 2005). Tinnitus may cause many audiological, cognitive, and neurological issues ranging from hearing and attention deficits to anxiety, annoyance, irritability, disturbed sleep patterns, and depression (Zeng et al., 2011; Zhang, 2013).

Tinnitus may be the only or most important symptom, or it may be a component of an otovestibular complaint (Van de Heyning et al., 2007). Tinnitus as such is not an abnormal sensation. Most people will experience tinnitus after a couple of minutes in a silent anechoic room. Tinnitus will also occur after intense noise exposure for some hours in the majority of normal hearing people. Loud noises, such as those from heavy equipment, chain saws and firearms, are common sources of noise-related hearing loss (NRHL), as are portable music players and earphones, and all these increase the risk of tinnitus. Tinnitus caused by short term noise exposure, such as attending a loud concert, usually goes away. In contrast, long-term exposure to loud sound can cause permanent damage and thereby increase the risk of developing tinnitus (Knipper et al., 2013).

Epidemiological studies performed in Western industrialized countries have found that tinnitus affects roughly $10 \%$ of the adult population (Hall et al., 2015). Of these, one third reported tinnitus as disturbing or very disturbing. For many of these patients (roughly 1-2\%), tinnitus is a handicap that interferes significantly with their quality of life (severe tinnitus). Severe tinnitus can be very debilitating, often affecting the primary functions of emotions, hearing, sleep, and concentration.

Hearing loss is the most important risk factor for developing tinnitus. Most patients of tinnitus have a related sensorineural hearing loss (SNHL), attributable to aging, noise exposure, or chronic otitis media (Holm et al., 2005). While neural mechanisms causing tinnitus and HL are not identical, the incidence of tinnitus is highly correlated with HL. Although not all individuals experiencing tinnitus have HL, those who have HL experience an $83 \%$ higher risk of developing tinnitus over those who do not have a HL.

Since the prevalence of HL increases with age, the prevalence of tinnitus also increases with age, peaking between 60 and 69 years of age. The prevalence of frequent tinnitus is highest among older adults, more common in men than in women, and in adults with hypertension, hear- ing impairment, loud noise exposure, or generalized anxiety disorder (Knipper et al., 2013). For the industrialized countries, this translates into an ever-growing number of tinnitus sufferers. Because of the high incidence rate, the economic impact of tinnitus on the health-care system is relatively large (Vio and Holme, 2005).

Therefore, tinnitus is a frequent and often debilitating condition, which is difficult to treat. Historically, tinnitus had been thought to reside solely within the ear itself. Recent animal and human imaging studies have linked tinnitus to abnormal, usually hyper-excitable brain activities that are likely caused by absent or disordered auditory signals, and can be modulated by the limbic system (Zeng et al., 2011). There is increasing evidence that tinnitus is related to alterations of neuronal functioning in the central auditory system. Tinnitus, as an auditory phantom perception, seems to be the correlate of maladaptive attempts of the brain at reorganization due to distorted sensory input (Kleinjung, Steffens, Struz, \& Langguth, 2009). Normally, the peripheral auditory nerve fibres are spontaneously active in quiet (Rubinstein, Tyler, Johnson, $\&$ Brown, 2003). This spontaneous firing of the auditory nerve is due to continuous release of neurotransmitter by the inner hair cell synapses (Rubinstein et al., 2003). Early theories about the peripheral origin of tinnitus suggest that loss of this normal pattern of spontaneous activity can lead to abnormal central auditory activity perceived as sound. This theory is consistent with the above mentioned facts that most tinnitus is associated with HL and most HL is associated with loss or alteration of spontaneous activity. The neural mechanisms of tinnitus are further discussed in Section 2.

As tinnitus is not apparent to others, procedures for its diagnose rely mostly on the subjective report of the patient. There exist many subjective measures for the tinnitus severity, and some objective assessment based on brain activity imaging techniques. They will be more closely analysed in Section 3.

Several therapeutic approaches, including counselling and behavioural therapy, the provision of hearing aids and cochlear implants (CI), and sound therapy devices can be effective for many people (Kleine Punte, Meeus, \& Van de Heyning, 2010; Tyler et al., 2015). Tinnitus treatments are additionally reviewed in Section 4.

Finally, a new sound therapy technique, the generation of an Enriched Acoustic Environment consisting of sequences of gammatones with random frequency and amplitude proportional to the HL value at this particular frequency, is described in Section 5.

\section{TINNITUS MECHANISMS}

Although significant progress has been made to the elucidation of tinnitus mechanisms over the past 15 years, much remains to be learned. According to Sedley et al. (2015), tinnitus usually occurs when damage to the peripheral auditory system leads to spontaneous brain activ- 
ity that is interpreted as sound. The central auditory system compensates for diminished input by upregulating its responsiveness in central circuitries (Knipper et al., 2013). Central compensation that follows reduced auditory nerve activity may occur first at the level of the auditory brainstem, from where altered activity patterns then spread to ascending auditory nuclei. The relationship between HL and tinnitus is emphasized when HL and tinnitus spectra curves are represented in the same plot. As it can be seen in Figure 1, tinnitus spectra and HL curves seem to be inverse to each other.

According to Eggermont (2012), the triad of neural correlates associated with tinnitus include (see Figure 2):

- Hyperactivity: increase of spontaneous firing rate (SFR) at cortical and sub-cortical levels to compensate for a decrease of the SFR at the auditory nerve. Possibly related to changes in the balance of excitation and inhibition at multiple levels of the auditory pathway.

- Hypersynchrony: increase of neural synchrony in the cortex following a peripheral de-afferentation.

- Reorganization of the tonotopic map: leading to an over-representation in the cortical tonotopic map of edge frequencies.

More likely, tinnitus results from a combination of various mechanisms. For instance, decreases in intra-cortical inhibition and increases in spontaneous activity occurring after loss of peripheral input to central neurons could promote development of synchronous activity by prolonging postsynaptic depolarization and increasing the likelihood of temporally coincident inputs converging on synapses (Eggermont, 2012).
Many other authors suggest similar tinnitus mechanisms. Kleinjung et al. (2009) have demonstrated, with animal experiments, that reduced auditory input causes a dysbalance between inhibitory and facilitatory mechanisms throughout the central auditory pathways, which then results in reorganisation of the tonotopic map in the auditory cortex. This might represent a neuronal correlate of tinnitus. Accordingly, therapeutic strategies that either specifically compensate for HL or normalize auditory input (e.g. hearing aids or cochlear implants) have been shown consistently to attenuate tinnitus complaints. This is the basis of the treatments of tinnitus (see Section 4).

\section{TINNITUS MEASURES}

Tinnitus has many forms and many characteristics. However, tinnitus is not readily apparent to others, and

Figure 2: Schematic illustration of tinnitus as a compensation mechanism, at sub-cortical and cortical levels, to an auditory peripheral deprivation.

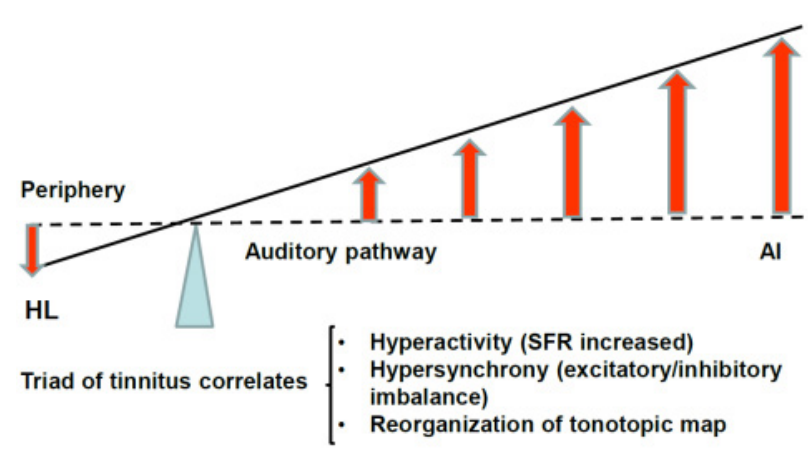

Figure 1: Schematic Hearing Loss (HL) and Tinnitus Spectrum (TS) rating of a tinnitus patient.

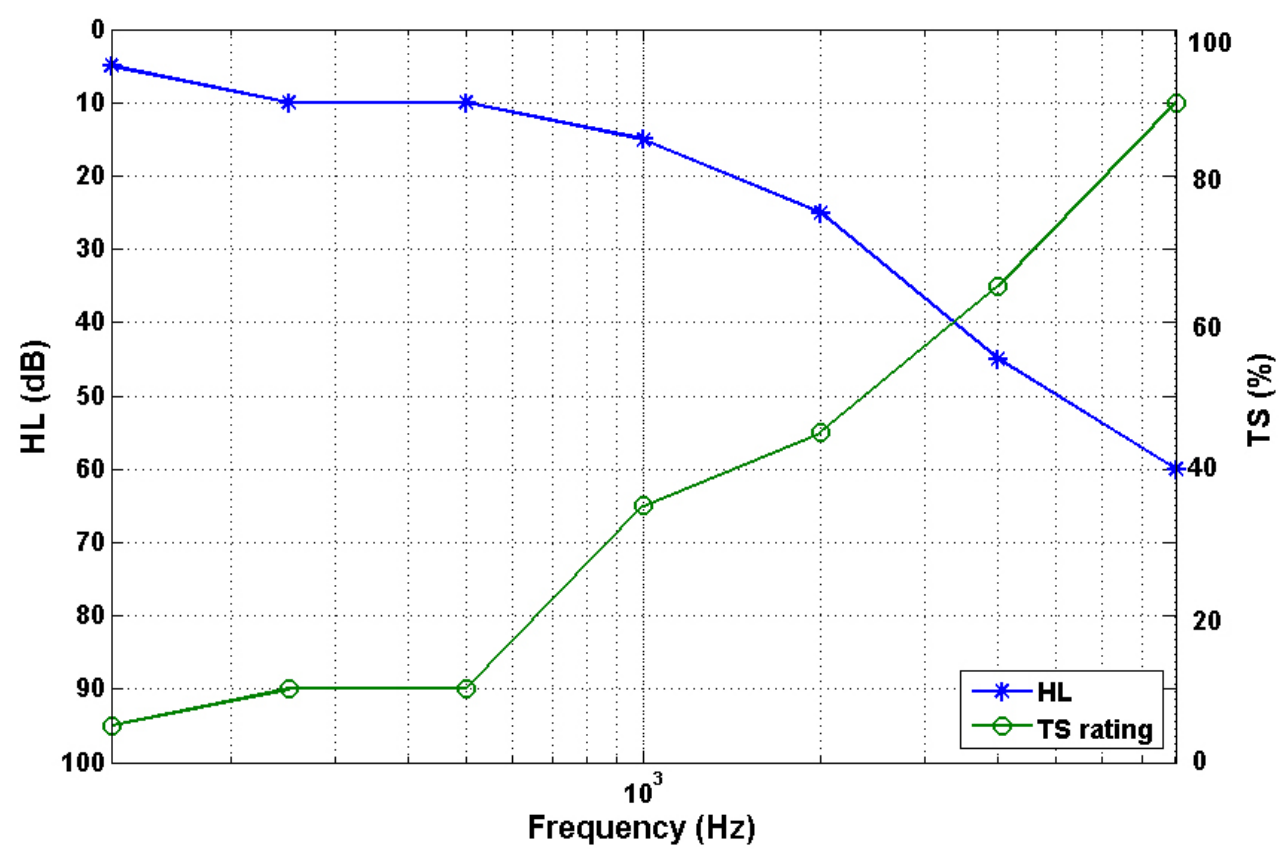


currently no objective procedures are yet established for the diagnosis of tinnitus (Langguth, Searchfield, Biesinger, \& Greimel, 2011). The assessment of the perceptual aspects of tinnitus is difficult. Only by listening to the patient can one find out whether a patient has tinnitus and what form of tinnitus he or she has. The case history is of high importance for a correct diagnosis in all areas of medicine; this is especially true for tinnitus, since it is fundamentally a self-report phenomenon. Moreover, the subjective nature of tinnitus is a challenge not only in the clinical management of the individual with tinnitus but also for research applications.

Over the past two decades, recognition has grown that measures for evaluating treatment outcomes must be designed specifically to have high responsiveness (Meikle, Stewart, Griest, \& Henry, 2008). There exist four major types of tinnitus measures, including psychoacoustic measures, various rating scales, self-report questionnaires concerning functional effects of tinnitus, and global outcome measures. In general, immediately obtainable outcome measures (psychoacoustic, rating scales, or single global measures) and longer term measures (questionnaires covering the negative effects of tinnitus) can be used for further work in tinnitus outcome assessment (Meikle et al., 2008).

Measures of tinnitus can be classified, depending on whether the intervention of subject is required or not, in subjective and objective (see Table 1). Subjective measures of tinnitus include psychoacoustic tests (pitch match, loudness, Minimum Masking Level [MML], or residual inhibition), rating scales (Visual Analog Scale [VAS], Numerical Rating Scale [NRS]) and questionnaires. Different questionnaires are available to assess specific aspects of patients with tinnitus. These questionnaires are score driven, which means that the responses to single items are scored and then summed or averaged (Langguth et al., 2011). Thus, total scores or subscale scores can be calculated.

Tinnitus questionnaires include the Tinnitus Severity Scale (TSS), the Tinnitus Questionnanire (TQ), the Tinnitus Handicap Questionnaire (THQ), the Tinnitus Handicap Inventory (THI), the Tinnitus Reaction Questionnaire (TRQ), the Tinnitus Severity Index (TSI), and others (Langguth et al., 2011). The THI is the most widely used tinnitus questionnaire, as evidenced by the number of citations. In a consensus meeting, the use of the THI has been recommended for clinical studies in order to facilitate comparability between studies (Langguth et al., 2007).

Objective measures of tinnitus are related to brain mapping techniques. Sedley et al. (2015) presented extensive intracranial recordings from an awake, behaving tinnitus patient during short-term modifications in perceived tinnitus loudness after acoustic stimulation (residual inhibition), permitting robust characterization of core tinnitus processes. Roberts, Bosnyak, Bruce, Gander, and Paul (2015) compared sound-evoked brain activity in subjects experiencing tinnitus with that of subjects of similar age and hearing function who reported not having tinnitus, finding significant differences between the brain activity of both groups.

Table 1: A summary of tinnitus measures.

\begin{tabular}{|c|c|c|c|}
\hline & Measurement technique & Examples & Comments \\
\hline \multirow{4}{*}{ Subjective } & Psychoacoustic tests & $\begin{array}{c}\text { Pitch match } \\
\text { Loudness match } \\
\text { Minimum Masking Level (MMN) } \\
\text { Residual inhibition }\end{array}$ & $\begin{array}{c}\text { Patients match pitch, loudness, masking } \\
\text { level, and residual inhibition of their } \\
\text { tinnitus by an automatic controlled device } \\
\text { (or even an app). }\end{array}$ \\
\hline & Rating scales & $\begin{array}{l}\text { Visual Analog Scale (VAS) } \\
\text { Numerical Rating Scale (NRS) } \\
\text { Others } \\
\end{array}$ & $\begin{array}{l}\text { Patients mark a tip in a graded scale } \\
\text { (1-100, for instance). }\end{array}$ \\
\hline & Questionnaires & $\begin{array}{l}\text { TSS, STSE, TQ, THSS, THI, TRQ, TCQ, } \\
\text { TCSQ, TSI, and many others }{ }^{\mathrm{a}}\end{array}$ & $\begin{array}{l}\text { They are designed to assess specific } \\
\text { aspects of patients related to tinnitus } \\
\text { (functional, emotional, psychological, } \\
\text { etc.). The final result is a score. }\end{array}$ \\
\hline & $\begin{array}{l}\text { Patient's perception of } \\
\text { treatment-related change }\end{array}$ & Answer to short, specific questions & \\
\hline \multirow[b]{2}{*}{ Objective } & Neural activity mapping & fMRI, PET, and others & They are expensive and time-consuming. \\
\hline & Transcranial mapping & $\begin{array}{l}\text { Changes in amplitudes and latencies of } \\
\text { ABR waves }\end{array}$ & $\begin{array}{l}\text { Changes in discharge rate and synchrony, } \\
\text { two neural correlates of tinnitus, should be } \\
\text { reflected in altered ABR waveform, which } \\
\text { would be useful to objectively detect } \\
\text { tinnitus and its localization to auditory } \\
\text { brainstem structures. }\end{array}$ \\
\hline
\end{tabular}

${ }^{a}$ TSS: Tinnitus Severity Scale; STSE: Tinnitus Severity Scale; TQ: Tinnitus Questionnaire; THSS: Multidimensional Tinnitus Inventory; THI: Tinnitus Handicap Inventory; TRQ: Tinnitus Reaction Questionnaire; TCQ: Tinnitus Cognition Questionnaire; TCSQ: Tinnitus Copying Style Questionnaire; TSI: Tinnitus Severity Index. 
Das, Wineland, Kallogjeri, and Piccirillo (2012) claimed the use of the cognitive deficits associated with tinnitus as an objective measure of tinnitus severity. Their study utilised the Brain Speed Test (BST), a computerized assessment. While tinnitus is a subjective perception, measuring cognitive deficits may objectively measure the impact of tinnitus on a patient's life. Their hypothesis is that the cognitive impact of tinnitus can be demonstrated by slow processing speeds after controlling for depression and somatization. Their study investigated the relationship between self-reported tinnitus severity, cognitive processing speed, and psychiatric co-morbidities.

Changes in discharge rate and synchrony, two neuronal correlates of tinnitus, should be reflected in altered Auditory Brainstem response (ABR) waveforms, which would be useful to objectively detect tinnitus and its localization to auditory brainstem structures (Dehmel, Eisinger, \& Shore, 2013). Therefore, Dehmel et al. (2013) analysed latencies and amplitudes of the first five ABR waves at supra-threshold sound intensities and correlated ABR abnormalities with the results of the behavioural tinnitus testing. Early ABR wave amplitudes were increased for animals with tinnitus, possibly stemming from hyperactivity and hypersynchrony underlying the tinnitus percept. Animals that did not develop tinnitus after noise exposure showed the opposite effect, a decrease in wave amplitudes for the later waves. Changes in latencies were only observed in tinnitus animals, which showed increased latencies. Thus, tinnitus-induced changes in the discharge activity of the auditory nerve and central auditory nuclei should be represented in the ABR.

\section{TINNITUS TREATMENTS}

Although pharmacotherapy for tinnitus is the subject of intense efforts, the development of an international standard treatment protocol for chronic tinnitus is still in its early stages (Chang \& Zeng, 2012). A review evaluating 69 randomised clinical trials, comparing drug and non-drug treatments for subjective tinnitus, found that no treatment could be considered well established in terms of providing long-term reduction of tinnitus in excess of placebo effects (Dobie, 1999).

Arguably more than any other otologic disorder, tinnitus remains refractory to current therapy. Masking is an effective management strategy for some patients, and unblinded, uncontrolled clinical experience suggests that Tinnitus Retraining Therapy (TRT) may benefit others (Rubinstein et al., 2003). Antidepressants are effective if depression coexists with the tinnitus. Likewise, with co-morbid anxiety, anxiolytics may be of benefit. Yet, none of the above therapeutic strategies actually decreases the loudness of tinnitus in the absence of a masking stimulus. In words of Zeng et al. (2011), “despite intensive research into therapeutic options, including surgery, pharmacotherapy, and stimulation with lasers and mag- netic fields, there is no FDA-approved treatment for tinnitus at present" (p. 61).

New approaches are being explored, including cochlear implants for patients with unilateral HL and severe tinnitus, brain stimulation through transcranial magnetic stimulation, and brain stimulation. However, at present, there is no "cure" for tinnitus (Tyler et al., 2015).

Some hypotheses suggest an initial reversible phase and a later, more irreversible phase after two to three years (Van de Heyning et al., 2007). This early aberrant tinnitus can be reversed by appropriate acoustic stimulation, which has been shown to not only mask tinnitus but also to produce varying degrees of residual inhibition (RI). Recent studies of human subjects confirm that acoustic behavioural training modifies neural dynamics in the auditory cortex. These results, which are likely to depend on processes occurring in the cochlea as well as in the brain, suggest a sound therapy when tinnitus occurs. When tinnitus subjects are trained explicitly at pitch discrimination using single pure tones in the region of HL, the tinnitus percept can diminish for the trained frequencies while leaving the perception of nearby tinnitus frequencies intact (Eggermont \& Roberts, 2004).

Sound therapy effectiveness is often based on continuation of RI after the stimulus is removed. The dependence of RI on stimulus characteristics such as centre frequency, bandwidth, intensity, duration, and other parameters are still not well understood nor are the mechanism for the wide variability in RI for individuals. Thus, there is considerable experimentation in both the strength and type of stimulus send and the delivery method employed in an attempt to maximize RI (Lenhardt, 2004).

Different sound therapies for tinnitus treatment have been proposed, such as masking, Tinnitus Retraining (TRT; Jastreboff \& Jastreboff, 2000), auditory discrimination training (ADT; Flor, Hoffmann, Struve, \& Diesch, 2004; Herraiz, Diges, \& Cobo 2007; Herraiz, Diges, Cobo, \& Aparicio, 2009; Herraiz, Diges, Cobo, Aparicio, \& Toledano, 2010; Herraiz, Diges, Cobo, Plaza, \& Aparicio, 2006), Phase-Out (TPO; (Lipman \& Lipman, 2007; Vermeire, Heyndrickx, De Ridder, \& Van de Heyning, 2007), and Neuromonics treatment (Davis, Paki, \& Hanley, 2007). Table 2 summarises the results of some of these therapies on tinnitus patients. The efficiency of the therapy, as measured by the percentage of patients that experience some grade of improvement, is shown in the third column. Although these therapies use different stimuli, authors claim similar tinnitus relief percentages. It is surprising that so distinct sound stimuli can produce similar effects in tinnitus patients. Perhaps, it is a consequence of the adaptive plasticity of the central auditory system (CAS; Formby, Sherlock, \& Gold, 2003; Noreña \& Eggermont, 2005). Sound therapies assume that the CAS is plastic and its input can be reset to normal values by exposure to enriched background sound. Although the correlation between the sound stimulation and the beneficial effects on the tinnitus has been shown, it is not still clear the dependence of the effectiveness of the sound therapy 
Table 2: Characteristics of different sound therapies.

\begin{tabular}{|c|c|c|c|}
\hline Sound therapy & Stimulus & Efficiency $(\%)^{a}$ & References \\
\hline $\begin{array}{c}\text { Tinnitus Retraining } \\
\text { Therapy (TRT) }\end{array}$ & $\begin{array}{l}\text { Wideband } \\
\text { noise }\end{array}$ & $75 \%$ with MTQ & Jastreboff \& Jastreboff (2000) \\
\hline $\begin{array}{c}\text { Auditory } \\
\text { Discrimination } \\
\text { Therapy (ADT) }\end{array}$ & $\begin{array}{l}\text { Oddball } \\
\text { paradigm }\end{array}$ & $\begin{array}{l}50 \% \text { with TQ and MTI } \\
50 \% \text { with VAS and THI }\end{array}$ & $\begin{array}{c}\text { Flor et al. (2004) } \\
\text { Herraiz, Diges, \& Cobo (2007) } \\
\text { Herraiz, Diges, Cobo, \& Aparicio (2009) } \\
\text { Herraiz, Diges, Cobo, Aparicio, \& Toledano (2010) } \\
\text { Herraiz, Diges, Cobo, Plaza, \& Aparicio (2006) }\end{array}$ \\
\hline $\begin{array}{l}\text { Tinnitus Phase-Out } \\
\text { (TPO) }\end{array}$ & Phase-out & $\begin{array}{c}57 \% \text { with THI } \\
60 \% \text { with VAS and TQ }\end{array}$ & Vermeire et al. (2007) \\
\hline Neuromonics & $\begin{array}{c}\text { Wideband } \\
\text { noise }+ \text { music }\end{array}$ & 91\% with TRQ & Davis et al. (2007) \\
\hline
\end{tabular}

aMTQ: Multidimensional Tinnitus Questionnaire; TQ: Tinnitus Questionnaire; MTI: Multidimensional Tinnitus Inventory; VAS: Visual Analog Scale; THI: Tinnitus Handicap Inventory; TRQ: Tinnitus Reaction Questionnaire

with the properties of the stimuli. Therefore, is there a sound stimulus that is best suited for tinnitus therapy?

\section{ENRICHED ACOUSTIC ENVIRONMENT}

Noreña and Eggermont (2005) demonstrated first that exposing cats to an Enriched Acoustic Environment (EAE) reverted the reorganization of the tonotopic map previously induced by a traumatizing noise. The stimulus was composed of tone-pips of random frequency (16 logarithmically spaced frequencies per octave) between 0.625 and $20 \mathrm{kHz}$, high-pass filtered at $8 \mathrm{kHz}$, and presented at a level of $80 \mathrm{~dB}$ sound pressure level. The EAE reverted the reorganization of the tonotopic map induced by peripheral NIHL. By stimulating the frequency region corresponding to the HL, they compensated for the decrease in firing rates in the auditory nerve fibres caused by HL and thereby prevented the cascade of central changes (release from inhibition) that would normally lead to cortical tonotopic map reorganization (Noreña \& Eggermont, 2005).

Schaette and Kempter $(2006,2008)$ demonstrated, using a computational model, that stimulating a neuron of the Cochlear Nucleus with a matched noise (which means a noise with the same spectrum as the HL curve) reverted the increase of firing rate and gain induced by tinnitus.

Noreña and Chery-Croze (2007) demonstrated that exposing patients to an EAE reverted the aberrant central gain produced in patients by hyperacusis. Hearing Loss, which causes a decrease in sensory inputs to the central auditory system, could cause an abnormal increase in central gain and consequently an auditory hypersensitivity. According to this model, compensating for the decrease in sensory inputs owing to HL could decrease the central gain and consequently reduce auditory hypersensitivity. Their study attempted to test this approach in patients reporting hyperacusis.

Herraiz et al. (2011) applied an EAE therapy to 21 patients of tinnitus from the waiting list of a hospital in the southwest of Madrid. In 11 of 21 patients, sound therapy was combined with counselling and pharmacological treatment. Six patients of the combined group and four of the only acoustic treatment were stimulated with continuous random noise weighted by the HL curve. The other 11 patients were treated with EAE stimuli. Tinnitus Handicap Inventory (THI) was significantly reduced in patients treated with EAE. Therefore, they demonstrated that a sound therapy based on an EAE produced relief on tinnitus patients.

Thus, EAE has been applied up to now as a sequence of either tone-pips or tone-bursts. The sequences of tonepips depend on a pair of parameters $(\alpha, \gamma)$, which determine the envelope of the tones, and therefore their spectra. The proper EAE therapy should then fix these two parameters so that the tone-pip spectra correspond to the tuning curves of the different places of the tonotopic map. Obviously, these frequency response curves depend on the particular species. It should be interesting to tune these parameters to the frequency response curves of the human basilar membrane. This leads in a natural way to the so-called auditory filters or gamma filters (Irino \& Patterson 1997; Katsiamis, Drakakis, \& Lyon, 2007; Lyon, 1997; Slaney, 1993). The-time domain counterpart of the gamma filters are the gammatones.

Patterson (1994) demonstrated that a gamma filter of 4th order provided an excellent approach to a human auditory filter with Equivalent Rectangular Bandwidth (ERB), also known as Critical Band, given by

$$
E R B=0.108 f_{0}+24.7,
$$

being $f_{0}$ the central frequency of the band. Thus, the elements of the pair $(\alpha, \gamma)$, which corresponds to a gamma filter, are given by

$$
\begin{gathered}
\alpha=2 \pi E R B=2 \pi\left(0.108 f_{0}+24.7\right) \\
\gamma=4
\end{gathered}
$$

In this way, a gamma filter is determined by just the central frequency of the band, $f_{0}$. A bank of gamma filters 
is usually utilised for simulating the movement of the basilar membrane within the cochlea. These filters are defined in such a way that their central frequencies are distributed along the frequency axis as a function of their bandwidth.

The equation for a sequence of gammatones is

(3) $E A E(\mathrm{t})=\sum_{m} A_{m} \frac{(2 \pi E R B)^{4}}{6}\left(t-\tau_{m}\right)^{3} e^{-2 \pi\left(0.108 f_{m}+24.7\right)\left(t-\tau_{m}\right)} \cos \left[2 \pi f_{m}\left(t-\tau_{m}\right)\right]$

Figure 3 shows a sequence of seven normalised gamma filters at octave band frequencies between $250 \mathrm{~Hz}$ and $16 \mathrm{kHz}$. The EAE therapy consisting of a sequence of gammatones with random frequencies and amplitudes matched to $\mathrm{HL}$ at those frequencies is therefore claimed as a sound stimulus for tinnitus relief. Based on the above-mentioned prior art, it is evident that EAE, as it matches the amplitude of each gammatone to the HL, is customized for each patient. Furthermore, it drives selectively each part of the damaged cochlea by the corresponding auditory filter, so that it provides the most refined and selective stimulus for the patient.

A Graphical User Interface (GUI) has been created to facilitate the design of an EAE at any audiological clinic (see Figure 4). Introducing the HL data for each frequency, the GUI provides the EAE stimuli to be heard by the patient in some prescribed way (for instance, one hour per day during three months). Hopefully, the time course of tinnitus measures (THI, VAS, MNL [Masking Noise Level]) should show a decreasing trend, as can be seen in Figure 5.

\section{SUMMARY AND CONCLUSIONS}

Many causes, including infections, trauma, exposure to high levels of noise, side-effects of certain drugs, and a range of physiological disorders may lead to damage or even loss of the auditory system, resulting in a hearing impairment, also named Hearing Loss (HL). Hearing Losses are measured as increments of hearing thresholds at different frequencies. An unfortunate consequence of HL is tinnitus, an aberrant sound percept which has not an external or peripheral signal correlate. Tinnitus as such is not an abnormal sensation. Most people will experience tinnitus after a couple of minutes in a silent anechoic room. Tinnitus will also occur after intense noise exposure for some hours in the majority of normal hearing people. Tinnitus that occurs every day for more than five minutes is reported by $10-15 \%$ of the population, and for $1-2 \%$ it affects their quality of life considerably (severe tinnitus). Severe tinnitus is a frequent and often debilitating condition, which is difficult to treat. There is increasing evidence that tinnitus is related to alterations of neuronal functioning in the central auditory system. Tinnitus, as an auditory phantom perception, seems to be the correlate of maladaptive attempts of the brain at reorganization due to distorted sensory input (homeostatic plasticity).

Sound therapies have demonstrated their capability to treat tinnitus, especially when combined with counselling. Most of these therapies rely in the capacity of sound to revert the plastic changes, at sub-cortical and cortical auditory levels, to alleviate tinnitus. One of these, the Enriched Acoustic Environment (EAE), provides the chance to design sound stimuli customised for each patient.

Figure 3: Normalised gamma filters for octave band frequencies between $250 \mathrm{~Hz}$ and $16 \mathrm{kHz}$.

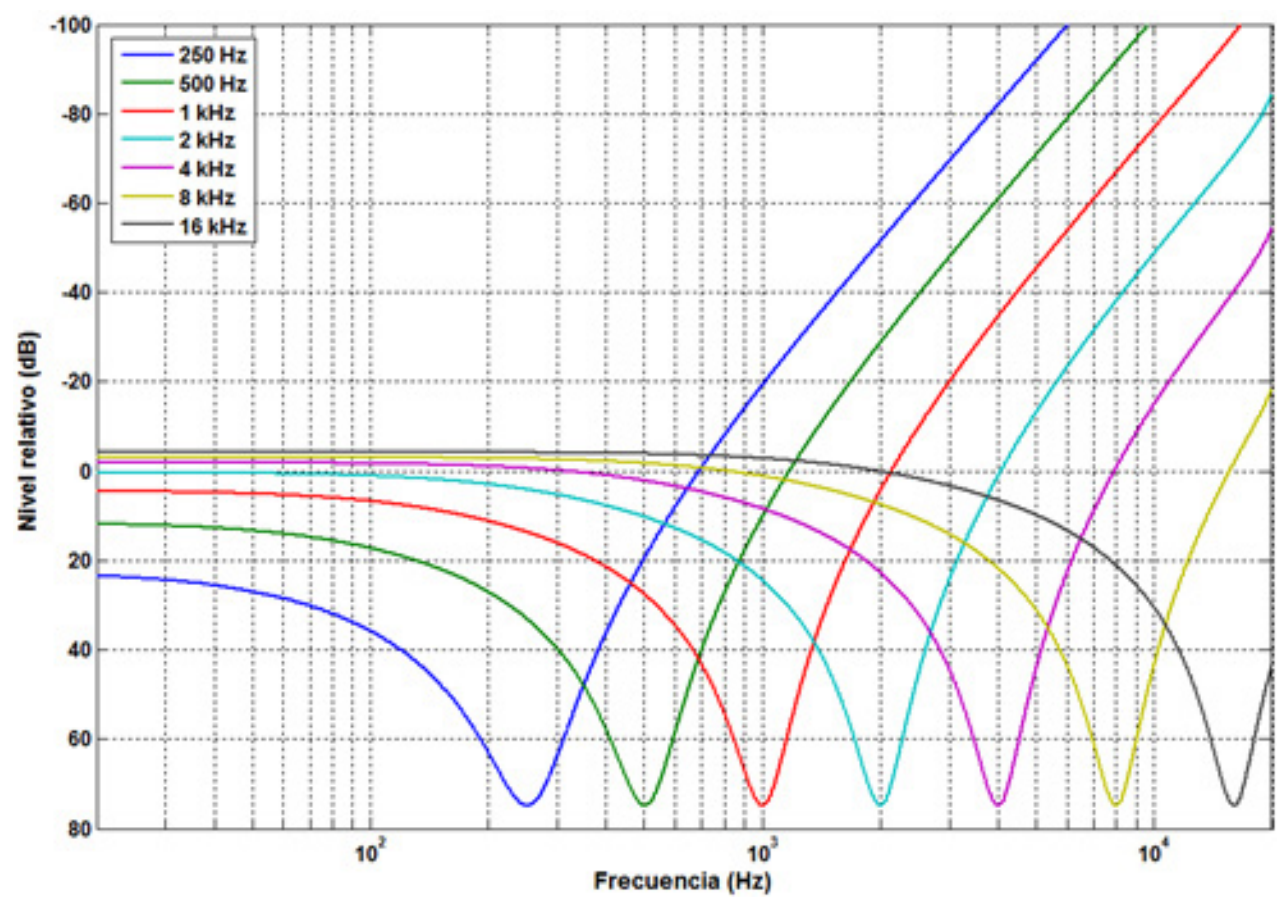


Figure 4: GUI for the design of Enriched Acoustic Environment (EAE) with gammatones.

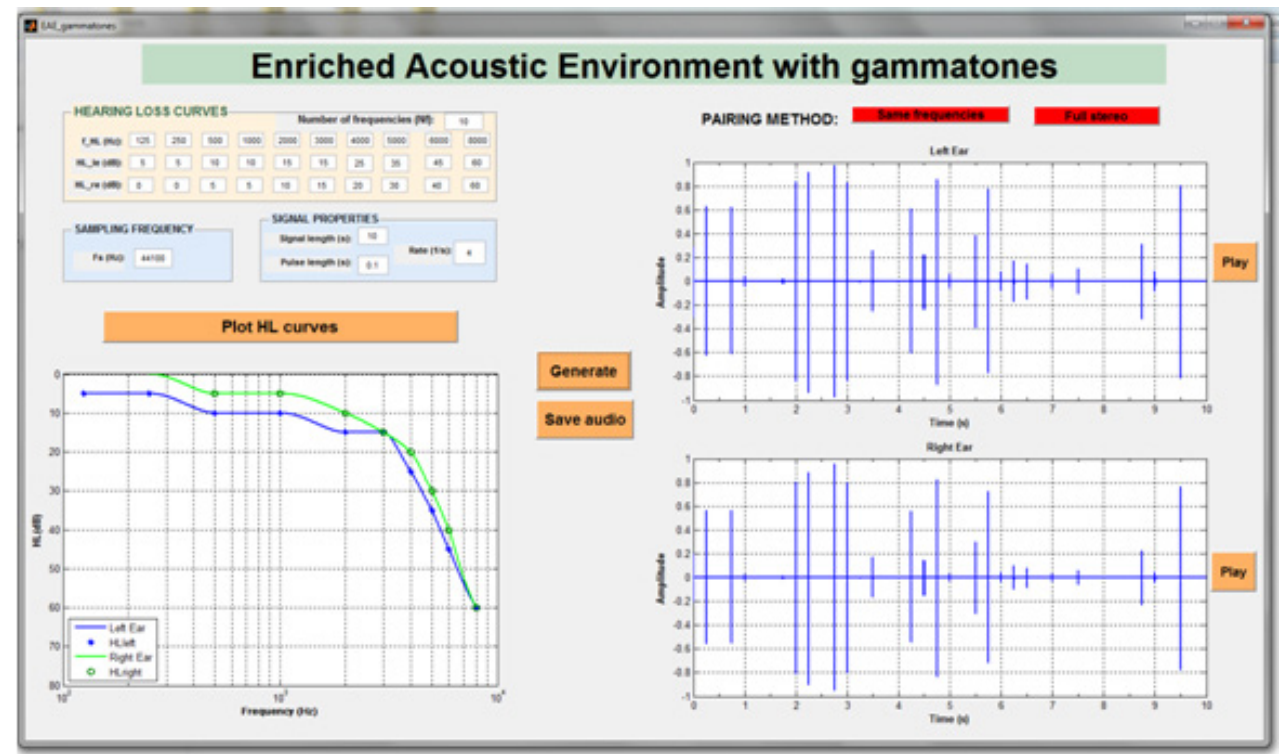

Figure 5: The time course of tinnitus measures. THI: Tinnitus Handicap Inventory; VAS: Visual Analog Scale; MNL: Masking Noise Level.

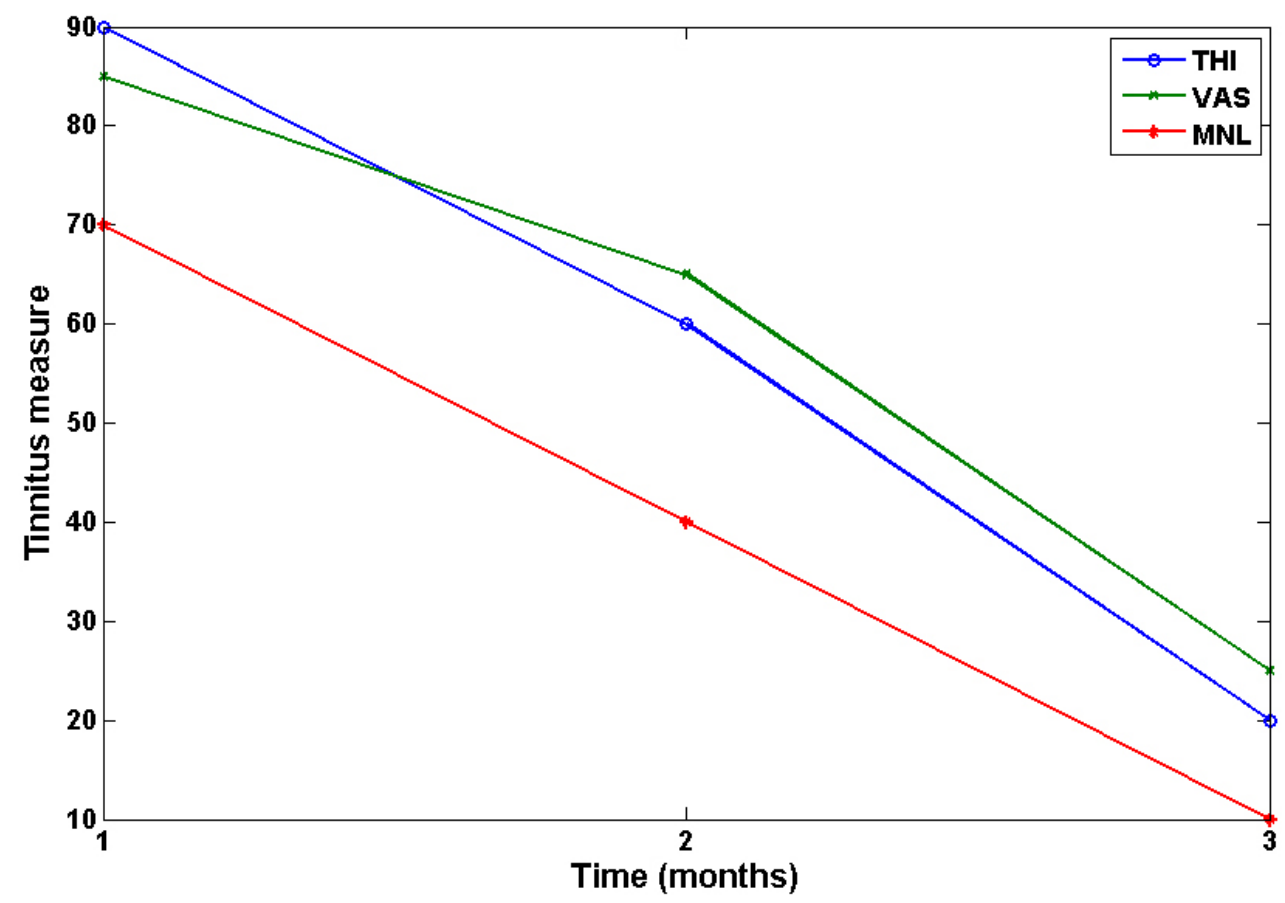

Moreover, when gammatones are used for EAE, each part of the cochlea is stimulated selectively. Each gammatone has random frequency within the hearing frequency band and amplitude matched to the patient HL at this frequency. Since the gammatone spectra correspond indeed to the human auditory filters, the proposed EAE is the more selective therapy. Moreover, as the amplitude of each gamma filter is matched to the HL at this frequency, it is customised for each patient.

\section{REFERENCES}

Chang, J. E., \& Zeng, F-G. (2012). Tinnitus suppression by electric stimulation of the auditory nerve. Frontiers in System Neuroscience, 6, 1-11. http://dx.doi.org/10.3389/fnsys.2012. 00019

Das, S. K., Wineland, A., Kallogjeri, D., \& Piccirillo, J. F. (2012). Cognitive speed as an objective measure of tinnitus. Laryngoscope, 122(11), 2533-2538. http://dx.doi.org/10.1002/ lary. 23555 
Davis, P. B., Paki, B., \& Hanley, P. J. (2007). Neuromonics tinnitus treatment: Third clinical trial. Ear \& Hearing, 28(2), 242-259. http://dx.doi.org/10.1097/AUD.0b013e3180312619

Dehmel, S., Eisinger, D., \& Shore, S. E. (2012). Gap prepulse inhibition and auditory brainstem-evoked potentials as objective measures for tinnitus in guinea pigs. Frontiers in Systems Neuroscience, 6, 1-15. http://dx.doi.org/10.3389/fnsys.2012.00042

Dobie, R. A. (1999). A review of randomized clinical trials in tinnitus. Laryngoscope, 109, 1202-1211. http://dx.doi.org/10.1097/ 00005537-199908000-00004

Eggermont, J. J. (2012). The neuroscience of tinnitus. Oxford (UK): Oxford University Press. http://dx.doi.org/10.1093/acprof:o so/9780199605606.001.0001

Eggermont, J. J., \& Roberts, L. E. (2004). The neuroscience of tinnitus. Trends in Neurosciences, 27(11), 676-682. http://dx.doi. org/10.1016/j.tins.2004.08.010

Flor, H., Hoffmann, D., Struve, M., \& Diesch, E. (2004). Auditory discrimination training for the treatment of tinnitus. Applied Psychophysiology and Biofeedback, 29, 113-120. http://dx.doi. org/10.1023/B:APBI.0000026637.77671.f4

Formby, C., Sherlock, L. P., \& Gold, S. L. (2003). Adaptive plasticity of loudness induced by chronic attenuation and enhancement of the acoustic background. Journal of the Acoustical Society of America, 114, 55-58. http://dx.doi.org/10.1121/1.1582860

Hall, D. A., Haider, H. Kikidis, D., Mielczarek, M., Mazurek, B., Szczepek, A. J., \& Cederroth, C. R. (2015). Toward a global consensus on outcome measures for clinical trials in tinnitus. Trends in Amplification, 19, 1-7. http://dx.doi.org/10.1177/2331216515580272

Herraiz, C., Diges, I., \& Cobo, P. (2007). Auditory discrimination therapy (ADT) for tinnitus management. Progress in Brain Research, 166, 467-471. http://dx.doi.org/10.1016/S0079-6123(07)66045-2

Herraiz, C., Diges, I., Cobo, P., \& Aparicio, J. M. (2009). Cortical reorganisation and tinnitus: Principles of auditory discrimination therapy for tinnitus management. European Archives of Otorhinolaryngology, 266, 9-16. http://dx.doi.org/10.1007/ s00405-008-0757-y

Herraiz, C., Diges, I., Cobo, P., Aparicio, J. M., \& Toledano, A. (2010). Auditory discrimination training for tinnitus treatment: The effect of different paradigms. European Archives of Otorhinolaryngology, 267(7), 1067-1074. http://dx.doi.org/10.1007/ s00405-009-1182-6

Herraiz, C., Diges, I., Cobo, P., Noreña, A., Hernández, J., \& Aparicio, J. M. (2011). Enriched acoustic environment with spectrum matched to the patient hearing loss curve for tinnitus sound therapy. International Tinnitus Seminar, March 16-19, Florianópolis (Brazil).

Herraiz C., Diges I., Cobo P., Plaza G., \& Aparicio, J. M. (2006). Auditory discrimination therapy (ADT) for the tinnitus management: Preliminary results. Acta Otolaryngologica, 126(Suppl. 556), 80-83. http://dx.doi.org/10.1080/03655230600895614

Holm, A. F., Staal, M. J., Mooij, J. J. A., \& Albers, F. W. J. (2005). Neurostimulation as a new treatment for severe tinnitus: A pilot study. Otology \& Neurotology, 26(3), 425-428. http://dx.doi. org/10.1097/01.mao.0000169784.15083.61

Irino, T., \& Patterson, R. D. (1997). A time-domain, level-independent auditory filter: The gammachirp. Journal of the Acoustical Society of America, 101, 412-419. http://dx.doi.org/10.1121/1.417975

Jastreboff, P. J., \& Jastreboff, M. M. (2000). Tinnitus Retraining Therapy (TRT) as a method for treatment of tinnitus and hyperacusis patients. Journal of the American Academy of Audiology, 11(3): 162-177.

Katsiamis, A. G., Drakakis, E. M., \& Lyon, R. F. (2007). Practical gammatone-like filters for auditory processing. EURASIP. Journal on Audio, Speech, and Music Processing, Article ID 63685. http://dx.doi.org/10.1155/2007/63685

Kleine Punte, A., Meeus, O., \& Van de Heyning, P. (2011). Cochlear implants and tinnitus. In A.G. Møller, B. Langguth, D. DeRidder \& T. Kleinjung, Textbook of tinnitus (pp. 619-624). Springer Science + Business Media. http://dx.doi.org/10.1007/978-1-60761-145-5 77

Kleinjung, T., Steffens, T., Struz, J., \& Langguth, B. (2009). Curing tinnitus with a Cochlear Implant in a patient with unilateral sudden deafness: A case report. Cases Journal, 2, 7462-4. http:// dx.doi.org/ 10.1186/1757-1626-2-7462
Knipper, M., Van Dijk, P., Nunes, I., Rüttiger, L., \& Zimmermann, U. (2013). Advances in the neurobiology of hearing disorders: Recent developments regarding the basis of tinnitus and hyperacusis. Progress in Neurobiology, 111, 17-33. http://dx.doi. org/10.1016/j.pneurobio.2013.08.002

Langguth, B., Goodey, R., Azevedo, A., Bjorne, A., Cacace, A., Croccceti, A., . . \& \& Vergara, R. (2007). Consensus for tinnitus patient assessment and treatment outcome measurement: Tinnitus Research Initiative meeting, Regensburg, July 2006. Progress in Brain Research, 166, 525-536. http://dx.doi. org/10.1016/S0079-6123(07)66050-6

Langguth, B., Searchfield, G. D., Biesinger, B., \& Greimel, K. V. (2011). History and questionnaries. In A.G. Møller, B. Langguth, D. DeRidder \& T. Kleinjung, Textbook of tinnitus (pp. 387-404). Springer Science + Business Media. http://dx.doi. org/10.1007/978-1-60761-145-5 47

Lenhardt, M.L. (2004). Tinnitus devices. Retrieved from http:// www.tinnitus.vcu.edu/Pages/Tinnitus\%20Devices.pdf

Lipman, R. I., \& Lipman, S. P. (2007). Phase-shift treatment for predominant tone tinnitus. Otolaryngology-Head and Neck Surgery, 136(5), 763-768. http://dx.doi.org/10.1016/j.otohns.2006.10.046

Lyon, R. F. (1997). All-pole models of auditory filtering. In E.R. Lewis et al., Diversity in auditory mechanics (pp. 205-211). Singapore: World Scientific

Meikle, M. B., Stewart, B. J., Griest, S. E., \& Henry, J. A. (2008). Tinnitus outcomes assessment. Trends in Hearing, 12(3), 223235. http://dx.doi.org/10.1177/1084713808319943

Noreña, A. J., \& Chery-Croze, S. (2007). Enriched acoustic environment rescales auditory sensitivity. NeuroReport, 18(12), 12511255. http://dx.doi.org/10.1097/WNR.0b013e3282202c35

Noreña, A. J., \& Eggermont, J. J. (2005). Enriched acoustic environment alter noise trauma reduces hearing loss and prevents cortical map reorganization. Journal of Neuroscience, 25(3), 699705. http://dx.doi.org/10.1523/JNEUROSCI.2226-04.2005

Patterson, R. D. (1994). The sound of a sinusoid: Spectral models. Journal of the Acoustical Society of America, 96, 1409-1418. http://dx.doi.org/10.1121/1.410285

Roberts, L. E., Bosnyak, D. J., Bruce, I. C., Gander, P. E., \& Paul, B. T. (2015). Evidence for differential modulation of primary and nonprimary auditory cortex by forward masking in tinnitus. Hearing Research, 327, 9-27. http://dx.doi.org/10.1016/j.heares.2015.04.011

Rubinstein, J. T., Tyler, R. S., Johnson, A., \& Brown, C. J. (2003). Electrical suppression of tinnitus with high-rate pulse trains. Otology \& Neurolology, 24(3): 478-485. http://dx.doi. org/10.1097/00129492-200305000-00021

Schaette, R., \& Kempter, R. (2006). Development of tinnitus-related neuronal hyperactivity through homeostatic plasticity after hearing loss: A computational model. European Journal of Neuroscience, 23(11), 3124-3138. http://dx.doi.org/10.1111/j. 1460-9568.2006.04774.x

Schaette, R., \& Kempter, R. (2008). Development of hyperactivity after hearing loss in a computational model of the dorsal cochlear nucleus depends on neuron response type. Hearing $R e$ search, 240(1-2), 57-72. http://dx.doi.org/10.1016/j.heares. 2008.02 .006

Sedley, W., Gander, P. E., Kumar, S, Oya, H., Kovach, C. K., Nourski, K. V., . . \& \& Griffiths, T. D. (2015). Intracranial mapping of a cortical tinnitus system using residual inhibition. Current Biology, 25(9), 1208-1214. http://dx.doi.org/10.1016/j.cub.2015.02.075

Slaney, M. (1993). An efficient implementation of the PattersonHoldsworth auditory filter bank (Technical Report No. 35). Apple Computer Inc.

Soleymani, T., Pieton, D., Pezeshkian, P., Miller, P., Gorgulho, A. A., Pouratian, N., \& De Salles, A. A. (2011). Surgical approaches to tinnitus treatment: A review and novel approaches. Surgical Neurology International, 2, 154. http://dx.doi. org/10.4103/2152-7806.86834

Tyler, R. S., Keiner, A. J., Walker, K., Deshpande, A. K., Witt, S., Killian, ... \& Gantz, B. (2015). A series of case studies of tinnitus suppression with mixed background stimuli in a cochlear implant. American Journal of Audiology, 24, 398-410. http:// dx.doi.org/10.1044/2015 AJA-15-0005 
Van de Heyning, P., Meeus, O., Blaivie, C., Vermeire, K., Boudewyns, A., \& De Ridder, D. (2007). Tinnitus: A multidisciplinary clinical approach. $B-E N T, 3$ (Suppl. 7), 3-10.

Vermeire, K., Heyndrickx, K., De Ridder, D., \& Van de Heyning, P. (2007). Phase-shift tinnitus treatment: An open prospective clinical trial. B-ENT, 3(Supp. 7), 65-69.

Vio, M. M., \& Holme, R. H. (2005). Hearing loss and tinnitus: 250 million people and a US $\$ 10$ billion potential market. Drugs Discovery Today, 10(19). 1263-1265. http://dx.doi.org/10.1016/ S1359-6446(05)03594-4
Zeng, F. G., Tang, Q., Dimitrijevic, A., Starr, A., Larki, J., \& Blevins, N. H. (2011). Tinnitus suppression by low-rate electric stimulation and its electrophysiological mechanisms. Hearing Research, 277(1-2), 61-66. http://dx.doi.org/10.1016/j.heares. 2011.03.010

Zhang, J. (2013). Auditory cortex stimulation to suppress tinnitus: Mechanisms and strategies. Hearing Research, 295, 38-57. $\mathrm{http}: / / \mathrm{dx}$.doi.org/10.1016/j.heares.2012.05.007 